\title{
Type 1 Diabetes: Causes, Symptoms and Treatments, Review with Personal Experience
}

\author{
Safia Kousar* \\ Biotechnology, Manipal Institute of technology (MIT), India
}

Submission: July 10, 2019; Published: August 06, 2019

*Corresponding author: Safia Kousar, Third year B Tech, Biotechnology, Manipal Institute of technology (MIT), Manipal, Karnataka, India

\begin{abstract}
Type 1 diabetes is an auto-immune disorder commonly occurring in the young. The exact cause of this type of diabetes is not yet known and most people suffering from this chronic illness do not know how to manage and avoid diabetic complications. Parents lack knowledge to help their child manage Type 1 diabetes leading to depression. The author herself is diagnosed with Type 1 diabetes and most explanations reported in this paper are from her personal experience and research. She hopes it will provide a better understanding and control of this disorder for those suffering from it.
\end{abstract}

Keywords:Type 1 diabetes; Auto-immune disorder; Blood glucose; Insulin; Hypoglycaemia; Hyperglycaemia; Diabetes mellitus; Pancreas; Juvenile diabetes; Gestational diabetes; Insulin resistance

Abbreviations: MODY: Maturity-Onset Diabetes of the Young; NDM: Neonatal Diabetes Mellitus; T1DM: Type 1 Diabetes Mellitus; T2DM: Type 2 Diabetes Mellitus; LADA: Latent Autoimmune Diabetes of Adults; DKA: Diabetic Ketoacidosis; GAD: Glutamic Acid Decarboxylase; ICAs: Islet Cell Cytoplasmic Autoantibodies; IA-2As: Insulinoma-Associated-2 Autoantibodies; IAAs: Insulin Autoantibodies; RER: Rough Endoplasmic Reticulum; CGMs: Continuous Glucose Monitoring Devices; GI: Glycemic Index

\section{Introduction}

'Diabetes Mellitus' happens when blood glucose/sugar becomes too high [1]. Blood glucose is the main type of sugar found in blood and is the main source of energy. Glucose comes from the food and is also made in the liver and muscles. The blood carries glucose to all of the body's cells to use for energy. Pancreas, an organ located between the stomach and spine, releases a hormone called insulin into the blood which carries glucose to all body's cells. Sometimes the pancreas doesn't make enough insulin or the insulin doesn't work the way it should, glucose then stays in the blood and doesn't reach cells. Blood glucose levels get too high and can cause diabetes [2]. The three main types of diabetes are Type 1, Type 2 \& Gestational Diabetes. People irrespective of gender and age can develop diabetes.

\section{Type 1 diabetes}

Type 1 diabetes or juvenile diabetes, develops most often in young people; however, type 1 diabetes can also develop in adults. In type 1 diabetes, the body no longer makes insulin or enough insulin because the body's immune system has attacked and destroyed the cells (pancreatic Beta cells) that make insulin [2]. Don't eat too much sugar, you will become diabetic-this is not true. A person with Type 1 diabetes developed the disease because their immune system destroyed the insulin-producing beta cells [3].

Some rare forms of diabetes result from mutations or changes in a single gene and are called as monogenic diabetes. Neonatal Diabetes mellitus (NDM) and Maturity-Onset Diabetes of the Young (MODY) are the two main forms of monogenic diabetes [4]. Diabetes occurring before the age of 6 months is more likely to be NDM rather than autoimmune Type 1 Diabetes Mellitus (T1DM). MODY, are a group of autosomal-dominant inherited disorders, where there is hyperglycaemia (high blood sugars) at an early age, generally of a mild nature. It results from beta-cell dysfunction, rather than insulin resistance. Mutations in at least eight genes have been linked to MODY. In addition to the typical young people with acute onset T1DM, there is an older group with the slower onset disease. They may present in middle age with apparent Type 2 Diabetes Mellitus (T2DM) but have evidence of autoimmunity as assessed by Anti-Glutamic Acid Decarboxylase (GAD antibody) measurements and ultimately become insulin dependent. This is referred to as Latent Autoimmune Diabetes of Adults (LADA) [1]. 


\section{Type 2 diabetes}

Type 2 diabetes or adult-onset diabetes, can affect people at any age, even children. However, type 2 diabetes develops most often in middle-aged and older people. People who are overweight and inactive are also more likely to develop type 2 diabetes. It usually begins with insulin resistance-a condition that occurs when fat, muscle, and liver cells do not use insulin to carry glucose into the body's cells to use for energy. As a result, the body needs more insulin to help glucose enter cells. At first, the pancreas keeps up with the added demand by making more insulin. Over time, the pancreas doesn't make enough insulin when blood sugar levels increase, such as after meals. If pancreas can no longer make enough insulin, it is type 2 diabetes [2].

\section{Gestational diabetes}

Gestational diabetes can develop when a woman is pregnant. Pregnant women make hormones that can lead to insulin resistance. All women have insulin resistance later in their pregnancy. If the pancreas doesn't make enough insulin during pregnancy, a woman develops gestational diabetes. Overweight or obese women have a higher chance of gestational diabetes. It most often goes away after the baby is born. However, a woman who has had gestational diabetes is more likely to develop type 2 diabetes later in life. Babies born to mothers who had gestational diabetes are also more likely to develop obesity and type 2 diabetes [2].

In addition, another type of diabetes called 'Diabetes Insipidus' is the inability of the kidneys to conserve water, resulting in large volumes of dilute urine \& frequent thirst (results from problems in pituitary gland \& kidneys) [5].

\section{Symptoms of Type 1 Diabetes}

a) Weight loss-Insufficient insulin prevents the body from getting glucose from blood into cells to use as energy. The body starts burning fat and muscle for energy, causing reduction in weight [5].

b) Fatigue

c) Frequent headaches due to high sugars

d) Excessive hunger

e) Chest burns \& Indigestion-When stomach can't empty quickly enough (gastroparesis), unpleasant abdominal problems like nausea, vomiting, bloating, heartburn or feeling of fullness right after eating or long time afterwards experienced [5].

f) Excessive thirst \& frequent urination-Blood sugar rises, the kidneys cannot retain extra sugar which is dumped into the urine, increasing urination \& causes dehydration. Significant loss of potassium \& other salts in excessive urination [5].

g) Breathlessness when exercising, including walking h) Diabetic Ketoacidosis (DKA)-In DKA body uses fat for fuel. Fat is converted to fatty acids and glycerol and fatty acids further converted to ketone bodies. Therefore, ketones become the alternative fuels for the body when cells are low on glucose for a prolonged period of time. Excess of ketones makes the blood acidic (ketoacidosis). A person becomes dehydrated. The body produces stress response, hormones (glucagon, growth hormone \& adrenaline) break down muscle, fat, liver cells into glucose \& fatty acids for use as fuel. If not treated might lead to coma and death of person [6].

The author experienced initial symptoms like weight loss (her weight dropped from $45 \mathrm{~kg}$ to $39 \mathrm{~kg}$ ), frequent urination, excessive thirst, excessive hunger, late periods \& less bleeding and frequent headaches. But she didn't take them seriously because she stays in a hostel and was completely involved in her studies and other normal day to day activities. Also, she had no history of any medical problems and diabetes was out of the question. She kept thinking that she had been losing weight due to improper diet. When she went back home during vacation, she experienced the symptoms of DKA (woke up breathless and went under a semi-unconscious state). Then she was informed by her doctors that she had been diagnosed with Type 1 diabetes.

\section{Causes of Type 1 Diabetes}

Type 1 diabetes is an auto-immune disorder in which the immune system destroys tiny portion of the pancreatic tissue (The organ which produces the insulin hormone). It is diagnosed when $90 \%$ of beta-cells that produce insulin are destroyed. It is a genetic disease, but not hereditary. Those likely to develop type Diabetes have a gene mutation that causes the antibodies. Pancreas need enzyme Glutamic Acid Decarboxylase (GAD) to function normally. Antibodies that target this enzyme are called GAD antibodies. Other antibodies associated with type 1 diabetes include:

i. Islet cell cytoplasmic autoantibodies (ICAs)

ii. Insulinoma-associated-2 autoantibodies (IA-2As)

iii. Insulin autoantibodies (IAAs) (more common in children than adults)

The more autoantibodies, more aggressive are the autoimmune attack [7]. The genetic code for diabetes is present on one of the genes (chromosome 6). It was reported that the Human Leukocyte Antigen (HLA-DR) genes are responsible for causing Type 1 diabetes. But genes are like the loaded gun, it is the environmental factors which act as the trigger. For those who have the gene (HLA-DR), a trauma or viral infection (flu) triggers the onset. Rotavirus infects the pancreas by hijacking a receptor on pancreas cells, causing cell death. This infection is thought to trigger the autoimmune destruction of beta cells. Some other triggers include bacterial infection, unidentified components that cause autoimmune reaction, chemical toxins in food, underlying genetic disposition [7]. 
In case of the author she had proper diet back at home, but when she was left to live by herself in a hostel, due to improper food at the mess she started substituting food for junk food like chips, burgers, pizzas, etc. She never had a sweet tooth previously but all of a sudden, she started taking too many sweets perhaps a chocolate or ice-cream a day. As a result, there was a zero intake of nutrition. Also, she is a sensitive person and used to stress for every little thing. There is no history of type 1 diabetes in her family. So, it was a shock for her when she was diagnosed. She blames her improper diet and her carelessness to not take care of her body when it is her prime age to do so.

\section{Treatment of Type 1 Diabetes}

\section{Insulin}

Insulin discovery: Insulin was discovered in 1921 by Banting, Best, Macleod and Collip in acid-ethanol extracts of the pancreas. It was first used for treatment in January 1922. By October 1923, insulin was available widely throughout North America and Europe. International recognition followed rapidly for its discoverers, and the 1923 Nobel Prize for Physiology or Medicine was awarded jointly to Banting and Macleod. The primary sequence of insulin was reported in 1955 by Sanger and the three-dimensional structure by Hodgkin in 1969. Proinsulin was discovered by Steiner in 1967, and the sequence of the human insulin gene by Bell in 1980. Yalow and Berson invented the radioimmunoassay for insulin in 1956. The presence of insulin receptors was deduced in 1971 by Freychet, and the receptor protein was isolated in 1972 by Cuatrecasas. Milestones in insulin pharmacology have included the invention of delayed - action preparations in the 1930s and 1940s; synthetic human insulin in 1979; and in the 1990s novel insulin analogs by recombinant DNA technology [1].

Physiology of pancreas (insulin secretion): Regulation of fuel homeostasis in mammals is dependent on numerous small endocrine organs known as islets of Langerhans, which are located in the pancreas. The islets of Langerhans $(2-3 \%$ of the total pancreatic mass) have Alpha, Beta (50-60\%), Delta cells. The beta-cells are the only source of the polypeptide hormone insulin, which comprises approximately 10\% ( $10 \mathrm{pg} / \mathrm{cell})$ of the total beta-cell protein. They are equipped to detect changes in circulating nutrients. They respond to elevated levels of nutrients by initiating an insulin secretory response which will induce the storage of circulating nutrients in liver, muscle and adipose tissue. They can also respond to a wide range of other signals, including hormones, neurotransmitters and neuropeptides, which modify the insulin secretory response to circulating nutrients. Complex interactions between islet cells, the autonomic nervous system and gastrointestinal incretin hormones allow precise integration between metabolic fuel intake, usage and storage [1].

Insulin biosynthesis: The gene for insulin is first transcribed in the beta cell nucleus to make a copy of premessenger ribonucleic acid (pre-mRNA), which is spliced leaving
mRNA carrying the genetic code for insulin. mRNA translated to make the protein preproinsulin that enters Rough Endoplasmic Reticulum (RER). RER cleaves off the leader sequences of amino acids, which serve only to get preproinsulin into RER. After cleavage of the amino acids the remaining protein, the proinsulin is received by Golgi complex. The Golgi complex removes a connecting peptide \& 2 amino acid pairs at each end of the proinsulin molecule. The middle left out a portion of proinsulin is insulin, which consists of 2 polypeptide chains. The insulin and c peptide (present in secretory vesicles of Golgi bodies) are released by exocytosis [8].

External administration of insulin: Insulin is a hormone which, if taken as pill gets destroyed by digestive processes and if inhaled damages the lungs. As it doesn't go through mucous membranes easily it cannot be inhaled into the sinuses and the same problem if taken as suppository. Hence, for quick delivery, the best place is circulatory system. Injecting subcutaneously takes much smaller needle, which doesn't have to penetrate far and which can be moved around to different locations [9].

\section{Precautions while injecting insulin:}

a. Should be injected into fatty areas like the upper part of thighs and stomach at a right angle to the skin after which the fold should be held for 5 - 10 seconds before removing the needle.

b. Should be injected in different places (1 centimeter from previous spot) (if injected in the leg, absorption in leg muscle will be more, so inject in the stomach, similarly do not inject in arms if playing sports like tennis).

c. Do not inject near moles/scars (insulin resistance more) [10].

d. Lipoatrophy-causes burning, resulting in a loss of fat tissue under the skin due to injecting multiple times in the same area.

e. Lipohypertrophy-condition resulting in additional fat deposits forming under the skin from too many insulin injections in the same location. Insulin absorption affected if continued to be injected into these same spots [11].

f. The insulin vial should be kept in 36-46-degree Fahrenheit. If colder than this it can freeze, if warmer than this it will be good for a while but eventually it starts to break down. Since Insulin is dissolved in water, keeping it in the cold helps to keep it from spoiling. When injecting holds the vial in hand until it no longer feels cold. If insulin is warm, the sting while injecting is not so bad. If insulin spoils, bacteria growing in it will break down the protein. It will not poison or make one sick; it just won't work very well [7].

g. Great care must be taken to monitor serum potassium levels repeatedly once insulin treatment is started as the concentration can drop precipitously [6]. 
The author's potassium levels dropped to $2.7 \mathrm{mmol} / \mathrm{l}$ (normal range $3.6 \mathrm{mmol} / 1-5.0 \mathrm{mmol} / \mathrm{l}$ ) during her initial intake of insulin. She also experienced swellings in her foot as there is retainment of water in the body during the first week of insulin injections.

Types of insulin: Two types of insulin are taken-Bolus and Basal insulin. Background or Basal insulin works all day long to steady blood glucose levels (long acting-24 hours) between meals and overnight. It includes Lantus (glargine), Detemir (levemir), and NPH (humulin N \& novolin N). Basal dose covers basal metabolic needs like heartbeat, breathing, brain function, digestion [7]. Lantus has a pH of 4 and gives burn if injected into muscle (acid crystals dissolve in the body). It may also act like rapid insulin with sudden onset and trigger hypos. It forms a pool of slightly acidic solution just under the skin which forms micro carbon dioxide bubbles. These bubbles delay the action of insulin (has slow and controlled action). Initially, it has little or no effect, but soon rises to a level, effectiveness, then remains pretty much same for next 24 hours when it is gone, and it doesn't produce any peaks, provides a consistent, mostly unchanging level for 24 hours and is almost useless in an emergency [12].

Mealtime or bolus insulin is taken to make sure meal doesn't raise glucose levels too high. Its action begins after 15 minutes of injection and it stays in system for 3-6 hours. It Includes Lispro (Humalog), Aspart (Novolog), Glulisine (Apidra), Humulin R and Novolin R. It is also injected to bring down glucose levels in case of an emergency [7].

\section{Future treatment methods}

Ongoing research to treat Type 1 diabetes involves Stem cell Therapy, Islet Transplantation, Pancreas transplantation and Gene therapy [1]. Efforts have also been made to develop inhaled insulin. Exubera, developed by Inhaled Therapeutics, became the first inhaled insulin to be marketed in 2006 by Pfizer, but poor sales led Pfizer to withdraw it in 2007. Afrezza a monomeric inhaled insulin was developed by Mannkind and approved by the FDA in 2014 [13].

The artificial pancreas (closed-loop system) is also now a viable treatment option. New devices have also been developed to achieve better blood sugar control [14].

\section{Control and Management of Type 1 Diabetes}

\section{Continuous glucose monitoring}

Frequent self-monitoring of glucose is essential (e.g. four or more times a day). This is done using Continuous Glucose Monitoring Devices (CGMs) which test interstitial fluid (fluid in between cells) of body \& convert glucose level of that to an estimate of what your blood glucose is. Blood glucose control should also be monitored by measurement of HbA1c every 2-6 months and it should be maintained at 6.5\%-7.5\%. New technologies for insulin administration and glucose monitoring include the use of pumps. Pump therapy provides increased lifestyle flexibility, and can reduce the risk for hypoglycaemia.
Real-time, continuous glucose monitoring devices provide detailed information on glucose patterns and trends, and alarms that are triggered by both hyperglycaemia and hypoglycaemia [1].

The author initially had an HbA1c of $15.1 \%$. In three months she brought it down to $10.2 \%$. Although it is still in poor control range, she is trying her very best to lower it down further. She hopes to see better results when she takes her next HbA1c test.

\section{Diet}

Strict diet needs to be maintained because diabetes can be controlled only with diet. The following diet control methods were adapted by the author after diagnosis with extensive research on various food items, its carbohydrate content and glycaemic index.

a) High fiber, low Glycemic Index (GI) (<55) (carbohydrate to blood glucose ratio), protein rich lentils, vegetables should be taken. Lean protein, unsaturated fats, \& carbs with more fiber take longer time to digest, satisfy hunger \& provide a steady stream of energy.

b) Complex carbohydrates are first broken down into simple carbohydrates \& then to glucose, this takes longer time, meaning blood sugar goes up more slowly \& they are less likely to be changed into fat. Solid carbohydrates increase blood sugars at slower rates (nuts like cashews, pistas, almonds, walnuts can be taken in limited amounts). Avoid liquid carbohydrates as they dissolve in the blood faster and increase blood glucose. Brown bread (wheat bread) taken with butter increases blood sugar at a slower rate (Butter has butyrate, which interacts with the microbiome in gastrointestinal tract) [15]. Brown rice is a healthy option over white rice.

c) Diabetes is more prone to cardiovascular diseases, hence avoid high cholesterol food. E.g.-prawns, meat, egg yolk

d) More protein intake is advised as protein manages secretion of hunger hormones (ghrelin) and elicits hormonal response of glucagon that diverts blood sugars to the muscles. This hormonal reaction lowers blood sugar levels, which helps decrease hunger pangs. Protein also prevents blood sugar swings to prevent mood changes and food cravings [15]. However, excess protein is excreted in urine (Albuminuria). Albuminuria is a common abnormality in patients with diabetes [1]. Protein rich foods include white meat (skinless chicken, tuna, salmon, sardines, soya and almonds).

e) Green vegetables (green leaves, okra, broccoli, anything green) are rich in protein, vitamins and other nutrients. Fruits like Apples, guavas, strawberries, watermelon, oranges, lime/lemon have a low GI and can be taken 1 per day. 
f) Opt for reduced or fat free dairy products.

g) Good amount of water (at least 2 liter per day) dissolves blood glucose and helps in lowering sugar levels.

h) Olive oil is preferred for cooking as it contains antioxidants which protect cells.

i) Omega 3-fats lower heart disease risks (salmon fish is a good option).

j) Deep fried foods should be avoided as they are extremely high in calories and completely destabilize blood sugar levels. Highly processed foods like soda, candy, white bread dump too much sugar into blood at once. Body stores extra as fat \& leaves hungry for more, hence need to be avoided [15].

k) Fatty foods like pizza with 1 single dose of insulin reduce blood glucose level too quickly risking hypo followed by a high reading (because rest meal is being digested \& glucose continues to be released into the blood stream) hence it is best to give 2 smaller insulin doses (one before $\&$ one after the food) [15].

l) Alcohol confuses the body into making too much insulin, interrupting other important functions to expel it so glucose levels drop. A glass of wine at dinner doesn't affect glucose levels the same night, but results in significantly lower levels the following morning, due to reduced growth hormone secretion during sleep. Alcohol blocks the production of glucose in the liver, which keeps emergency stores if glucose goes too low. Therefore, one needs to beware of hypos when consuming alcohol [15].

m) Insulin is taken to mainly digest carbohydrates so one should learn carbohydrate counting for the meals taken and adjust dosage accordingly. Make sure to check the nutritional values of the packaged foods.

n) Manage bolus insulin if eating out, by efficiently counting carbohydrates in the meal.

The author follows a very strict diet. She has properly learned to count carbs in her meals and boluses the right amount. She takes liquid carbohydrates (glucose water) whenever she experiences lows since liquid carbs directly mix into the blood and will rise glucose level faster. Her lows last for 15 minutes at most.

\section{Exercise}

Being physically active will help reach or stay at a healthy weight, helps insulin work better to lower blood glucose levels. One should aim for 30 to 60 minutes of activity most days of the week. While exercising, do not forget to carry glucose tablets or a carbohydrate-rich snack or drink, such as a fruit or juice, in case blood glucose levels go too low [2]. However, avoid exercising if blood glucose is greater than $250 \mathrm{mg} / \mathrm{dl}$ as there is not enough insulin, blood glucose increases right after exercise since muscles break down glycogen to glucose. Hence it is advised to check blood sugars before and after exercise [4].

The author goes for regular jogs, practices yoga daily and hits the gym whenever she has time. She always carries a chocolate with her in fear of low sugars and advices the same for all with type 1 diabetes.

\section{Sick Day Management}

Illness is stressful to body \& stress hormones that are released when sick cause the liver to produce more glucose, resulting in hyperglycaemia. Therefore, one should check their blood glucose frequently and adjust their insulin doses accordingly.

Cold medicines contain decongestants pseudoephedrine/ phenylephrine, which raise blood sugar levels. Antihistamines don't cause problems with blood sugar levels [16]. Other drugs that raise blood glucose concentrations include Glucocorticoids, Oral contraceptives (Progestogen - only pills, High - dose oestrogen, Levonorgestrel in combination pills), Thiazide diuretics (especially high dosages), Salbutamol Growth hormone (physiologic doses), Lamivudine, Pentamidine, Isoniazid, Streptozotocin etc. [1].

\section{Reasons for High Fasting Sugars}

Often one might witness high fasting sugars even if exercised and bloused right. The reasons for these abnormal fasting sugars include: -

a) Dawn's effect- when about to wake up, the body gets ready to burn more fuel, the liver releases more glucose into bloodstream. In diabetics there is no insulin to match the early morning rise; hence morning blood sugars are high. This occurs between $3 \mathrm{am}-8 \mathrm{am}$. This can be treated by increasing basal insulin dosage [17].

b) Somogyi effect (rebound hyperglycemia)-when too much or too little insulin is taken before bed, blood sugar drops sharply overnight. The body responds by releasing hormones that work against insulin, leading to hyperglycemia. One will experience a hypo in middle of the night [17].

c) To know if one is experiencing Dawns, or Somogyi phenomenon, one should check blood sugar at $3 \mathrm{am}$. If blood glucose is low (less than $70 \mathrm{mg} / \mathrm{dl}$ ) then it is Somogyi effect and if it is high (greater than $210 \mathrm{mg} / \mathrm{dl}$ ), it is Dawns phenomenon [17].

d) For women, during the luteal phase (time between ovulation and start of period) insulin resistance is high due to higher estrogen \& progesterone levels (during the week before the first day of period) and hence fasting sugar levels creep up \& stay up [18].

The author is currently experiencing high fasting sugars due to the reasons stated above. 


\section{Travelling}

Carry diabetic supplies (extra insulins, glucometer, injecting needles) in a separate bag. Carry enough snacks to avoid hypos. If travelling west, the 24-hour day is extended so cover these extra hours by taking rapid acting insulin (bolus insulin) with food. Then take background insulin at the usual time in the arrival time zone. If travelling east, the day is shortened. Take rapid acting insulin with meals and a reduced dose of background insulin at the normal time in the departure time zone. Then take a normal dose at normal time in the arrival time zone [19].

The author never forgets to carry her diabetic kit whenever she travels. She also always carries a handful of biscuits, chocolates to manage her lows.

\section{Conclusion}

Take Care of Diabetes Each Day

Do four things each day to help blood glucose levels stay in target range:

I. Follow a healthy eating plan.

II. Be physically active.

III. Manage insulin dosages.

IV. Monitor diabetes.

These things may seem like a lot to do at first. Make small changes until these steps become a normal part of day activity. Learn to balance insulin dosage with each meal and exercise to avoid hypos. Set a target blood glucose range and improve HbA1c (maintain it in between 6\%-7\%). Participate in marathons and attend diabetic camps to meet and learn from the experiences of other Type 1 diabetic people. Meditate, practice yoga and stay positive. Once learned to manage diabetes, people can lead a normal life and do not have to be afraid of diabetic complications.

The author advices all those diagnosed with type 1 diabetes to be patient and stay strong.

\section{Acknowledgements}

The author would like to acknowledge the support and guidance of her parents, sister, relatives, doctors, teachers, roommate (Gul Gandhi), hostel warden (Mrs. Aparna) and friends.

\section{References}

1. Richard Holt IG, Clive Cockram S, Allan Flyvbjerg, Barry J (2010) Textbook of Diabetes. Wiley-Blackwell, a John Wiley \& Son Ltd. publication, ( $4^{\text {th }}$ edn.), UK.

2. Michael Parchman L, Marion J Franz (2013) Your Guide to Diabetes: Type 1 and Type 2. NIH publication, No. 14-4016,

3. Suresh Lal B (2016) Diabetes: causes, symptoms and treatments. In book: Public health environment and social issues in India, (Chapter 5), ( $1^{\text {st }}$ edn).

4. Rubio-Cabezas O, Hattersley AT, Njolstad PR (2014) The diagnosis and management of monogenic diabetes in children and adolescents. Pediatric Diabetes 12: 33-42.

5. Michael Dansinger (2018) Diagnosis of diabetes, Webmd.

6. Melissa Conard Stoppler (2019) Diabetic ketoacidosis symptoms, causes, treatment and complications. eMedicine health.

7. Will Dubois (2019) Beta cell resurrection with diabetes. Diabetes mine.

8. Kenneth Saladin (2018) How is insulin produced in a cell? Anatomy and Physiology: The unity of form and function. ( $8^{\text {th }}$ edn).

9. Peter Rentzepis (2019) Switching to afrezza inhaled insulin: tips from diabetes educator. Diatribe Learn.

10. Barbara Brody (2018) Life with insulin injections. Webmd.

11. Lisa Leontis RN, Anp C (2016) Diabetes glossary. Endocrin Web.

12. Brian VSC (2019) The levemir and lantus burn. Diabetes forum.

13. McGill JB, Ahn D, Edelman SV, Kilpatrick CR, Santos Cavaiola T, et al. (2016) Making insulin accessible: Does inhaled insulin fill an unmet need? Advances in Therapy 33(8): 1267-1278.

14. Boughton CK, Hovorka R (2019) Is an artificial pancreas (closed-loop system) for type 1 diabetes effective? Diabet Med 36(3): 279-286.

15. Brunilda Nazario (2018) Best and worst foods for diabetes. Webmd.

16. Kathlevn Zelman (2014) Treating the flu in people with health risk. Medcinenet.

17. Gary Scheiner (2016) Dealing with dawn phenomena. Diabetes daily.

18. Gaete X (2010) Menstrual irregularities linked to type 1 diabetes. Fertil Steril, Endocrine Today.

19. Minesh Khatri (2017) Tips for travelling with diabetes. Webmd. 

CC This work is licensed under Creative BY DOl:10.19080/CRDOJ.2019.11.555817

Your next submission with Juniper Publishers
will reach you the below assets
- Quality Editorial service
- Swift Peer Review
- Reprints availability
- E-prints Service
- Manuscript Podcast for convenient understanding
- Global attainment for your research
- Manuscript accessibility in different formats
( Pdf, E-pub, Full Text, Audio)
- Unceasing customer service
Track the below URL for one-step submission
- https://juniperpublishers.com/online-submission.php

